\title{
Tecnologia para educar e transformar o cuidado em saúde
}

\author{
Zilma S. Nogueira Reis \\ Universidade Federal de Minas Gerais, Brasil
}

Inúmeros progressos tecnológicos têm revolucionado a maneira como cuidamos da saúde e tratamos as doenças. A presença, cada vez mais pervasiva da tecnologia em nosso cotidiano, pode viabilizar soluções simples e dinâmicas para prevenir agravos e monitorar a atenção à saúde, tornando tais recursos cada vez mais oportunos, eficientes e acessíveis a um grande número de pessoas. Espera-se contudo que a universidade cumpra o seu papel de vanguarda na ciência, mas que não se distancie da formação humanística da próxima geração de profissionais de saúde e afins, vocacionados para cuidar da vida.

Imensos são ainda os desafios advindos das inequidades socioeconómicas da sociedade contemporânea, que impactam na qualidade de vida e no direito universal do ser humano a uma vida saudável. A agenda das Nações Unidas em torno dos Objetivos do Desenvolvimento Sustentável envolve um plano de ação conjunto onde todos nós temos um papel: as políticas públicas, a universidade, a sociedade organizada em entidades apoiadoras e o próprio cidadão. $\mathrm{O}$ fardo da doença, da morte evitável ou das sequelas é sentido de forma contundente pelos mais pobres, pelos de baixa renda, especialmente em países com sistemas de saúde frágeis e pouco resilientes.

Neste volume da Revista Internacional em Língua Portuguesa (RILP), dedicado às ciências da vida e saúde, mostramos que as universidades dos países de língua oficial portuguesa têm um papel de destaque ao levantar questões que clamam por soluções e injúrias à saúde humana, mas também ao propor e testar inovações tecnológicas para mitigar tais problemas.

Reunimos dez contribuições, resultantes de experiências de grupos académicos de países lusófonos, que merecem ser compartilhadas com toda a comunidade da Associação das Universidades de Língua Portuguesa (AULP). Unidos pelo idioma comum e por desafios similares, os relatos mostram que a tecnologia, em seu sentido mais amplo, seja ela da informação, da comunicação, assistiva ou da educação, ultrapassam as barreiras das nações e podem fomentar a formação profissional, saúde e cuidado mediados por tecnologia, de forma presencial ou à distância. 
A importância da comunicação em saúde é o tema que abre o volume, com reflexões oportunas sobre partilhar ciência, promovendo reações como conscientização, opinião e compreensão. Em sequência, a comunicação direta com a sociedade para promover saúde, foi apresentada nas experiências com três aplicações para dispositivos móveis. Na primeira, o enfoque é o paciente recetor de cuidados paliativos, que carece de uma vigilância permanente e contínua. Os seus cuidadores beneficiaram das funcionalidades oferecidas diretamente nos seus telefones móveis, para auxílio na avaliação do seu estado geral e na assistência diária. Aprender jogando foi a proposta da aplicação Saia Justa. Voltada para adultos que se interessem pelos métodos contraceptivos, a apropriação de conceitos sobre planejamento familiar através de um jogo sério mostrou evidências de que essa forma de interação informacional pode ser efetiva. Já na aplicação Meu Pré-natal, mostrou-se que a orientação educativa para gestação saudável ultrapassa a consulta tradicional com o profissional de saúde. A informação de qualidade, em linguagem simples e acessível, a qualquer momento onde ela se faz necessária, pode solucionar dúvidas, alertar situações de risco e orientar a gestante na gravidez, parto e pós-parto.

O cuidado integrado e contínuo, com foco na prevenção de complicações das doenças crónicas em visitas domiciliares, mostrou-se capaz de reduzir internações nesta população. O estudo realizado na cidade do Rio de Janeiro, Brasil, é experiência de valor para cuidado de idosos, com menos intervenção e evitando-se os inconvenientes da hospitalização.

A qualidade da água na cidade do Uíge, em Angola, alerta que não podemos nos esquivar de graves desafios que ainda persistem no acesso à água adequada para consumo humano. A fragilidade dos sistemas de abastecimento, afetados por variações climáticas sazonais e o armazenamento em cacimbas são questões que se associam ao adoecimento por veiculação hídrica de agentes contaminantes.

A revisão sistemática de literatura sobre as fontes de estresse ocupacional em professores do Ensino Básico e Médio, destacou semelhanças entre Moçambique, Brasil e Portugal. O estudo apontou os desafios em relação à sobrecarga de trabalho, comportamento inadequado de alunos, condições precárias e inadequadas de trabalho docente.

Por outro lado, o "LABSIM - Experiência em simulação como metodologia de ensino" descreve uma formação em saúde a partir de ambientes de laboratório, focados no desenvolvimento de competências profissionais. O desafio da avaliação na educação médica por competência é também um relato que mostra a complexidade na formação do profissional do futuro, que enfrentará problemas cada vez mais desafiadores e universais. Ambos os estudos reforçam que a inovação, sem 
perder o foco nos desafios atuais da sociedade, é importante ferramenta complementar para mediar o ensino médico. Mesmo assim nada substitui as vivências nos cenários reais, especialmente naqueles que mais carecem de recursos e atenção. A legitimação social dos egressos, que passam a ser reconhecidos como competentes para atuar na profissão, carece também de uma ação formativa contínua, que ultrapassa os recintos académicos.

A última contribuição deste volume alerta para a importância do restaurante universitário na saúde dos estudantes. Ao ingressar na universidade, o estudante enfrenta novas relações sociais que podem trazer mudanças comportamentais, hábitos alimentares inadequados e adoção de práticas que causem risco à sua saúde.

Para compilar este volume com textos de qualidade, procurámos contribuições de autores experts em suas áreas. Os artigos foram revistos e avaliados por revisores científicos experientes que cederam o seu tempo para participarem na publicação desta edição, trabalho imprescindível que é de salientar. Como membros e apoiadores da AULP, a Universidade Federal de Minas Gerais (UFMG), no Brasil, e a Universidade de Coimbra, em Portugal, tiveram assim o privilégio de organizar, através de seus professsores, investigadores e revisores convidados, o presente trabalho. Registo aqui os meus sinceros agradecimentos. 